\title{
Radical Laparoscopic Treatment for Liver Hydatidosis
}

\section{B. Ramana}

Published online: 10 July 2013

(c) Société Internationale de Chirurgie 2013

General surgeons have traditionally been comfortable using intracavitary (i.e., the cavity of the cyst) approaches to the management of hydatidosis of the liver. Many ingenious approaches (including the use of a liposuction machine [1]) have been proposed to make the surgery easy and safe, with the prevention of spillage and anaphylaxis given the highest priority.

The emergence of laparoscopic liver surgery did not radically affect this approach, with surgeons focusing on effective cyst decompression while preventing spillage by chemical sterilization of the parasites in situ. Surgeons practicing in endemic zones see more complex cases of the disease, with multiple, large cysts, those presenting with complications like abscess or rupture, or those mimicking malignancy.

In situations like these, more radical approaches are not rare, although they are still unusual, as exemplified by the article by Ramia et al. [2] in this issue of World Journal of Surgery. It seems like a Hobson's choice to attempt a total cyst excision through a non-anatomical liver resection and thus to risk bleeding, versus trying a safer intracavitary approach with its risks of spillage and recurrence. The lack of hard evidence on this subject does not help us.

While several studies have shown the efficacy of laparoscopic liver resection, this is probably an example of a procedure better reserved for an ivory tower setting or a high-volume center. A liver surgeon with an occasional patient harboring a large cyst is better off doing a standard cystectomy, rather than trifling with a reluctant pericyst and its vascular rage.

B. Ramana $(\bowtie)$

Department of Minimal Access Surgery, Belle Vue Clinic,

Kolkata, India

e-mail: rambodoc@gmail.com
This is an age of the pervasive invasiveness of minimally invasive hi-tech gadgets. Can we not visualize a patient with a large hydatid cyst in the right lobe of the liver being dealt with by an enthusiastic young laparoscopic surgeon keen to try out the latest fad of radical cystectomy with the latest energy device (that purportedly would effortlessly fry all vessels, major and otherwise)? Such a situation would likely be a setting for a surgical disaster. In the Third World, this would likely be associated with loss of limb health, property, and mental peace, all affecting the care providers [3].

The reader would do well to note that most of these radical procedures would be feasible and safer when performed in the left lobe of the liver. The deep, intraparenchymal cyst is another beast, and needs a separate, preferably very experienced tamer.

Having burnt several fingers in the flames lit by offended inferior phrenic, hepatic, and caval veins, this writer is obliged to strike a warning note of caution, while applauding the Spanish results of this radical approach.

\section{References}

1. Al-Shareef Z, Hamour OA, Mohamed AA (2002) Laparoscopic treatment of hepatic hydatid cysts with a liposuction device. JSLS 6:327-330

2. Ramia JM, Poves I, Castellón C et al (2013) Radical laparoscopic treatment for liver hydatidosis. World J Surg. doi:10.1007/ s00268-013-2150-2

3. Ramana B (2013) The Third World. In: Schein M, Leppäniemi A, Rogers P, Rosin D (eds) Schein's common sense prevention and management of surgical complications. TFM Publishing Limited, Harley 